Martin Haigh

Fostering Deeper Critical Inquiry with Causal Layered Analysis, Journal of Geography in Higher Education, vol. 40 no.2 (2016)

DOI: $10.1080 / 03098265.2016 .1141185$

This version is available: https://radar.brookes.ac.uk/radar/items/97d71aff-464e-47c9-9827-07a7fc4d509f/1/

Available on RADAR: 10.03.2017

Copyright (C) and Moral Rights are retained by the author(s) and/ or other copyright owners. A copy can be downloaded for personal non-commercial research or study, without prior permission or charge. This item cannot be reproduced or quoted extensively from without first obtaining permission in writing from the copyright holder(s). The content must not be changed in any way or sold commercially in any format or medium without the formal permission of the copyright holders.

This document is the author's final accepted manuscript. 
Last prepublication draft (with post publication pagination) of: Haigh, M. 2016.

Fostering deeper critical inquiry with Causal Layered Analysis.

Journal of Geography in Higher Education 40(2), pp 164-181. [ISSN 309-8265].

DOI: 10.1080/03098265.2016.1141185. (Published on line: March 8, 2016).

\title{
Fostering Deeper Critical Inquiry with Causal Layered Analysis
}

\author{
Martin Haigh \\ Department of Social Sciences, Oxford Brookes University, Oxford OX3 OBP, UK.
}

\begin{abstract}
Causal Layered Analysis (CLA) is a technique that enables deeper critical inquiry through a structured exploration of four layers of causation. CLA's layers reach down from the surface 'litany' of media understanding, through the layer of systemic causes identified by conventional research, to underpinning worldviews, ideologies and philosophies, and deep subconscious drivers that manifest in myth and metaphor. CLA applies equally to Geographical research's socio-culturally-constructed situations and to the exploration of individual metacognition and motivation through Pedagogic research. Outcomes, explored through reflective journals and term papers, suggest that CLA helps more, especially middle-achievement, learners discover deeper structures within their studies.
\end{abstract}

Keywords: CLA; Causal Layered Analysis; Graduate Attributes, Critical Depth; Critical Thinking, Undergraduate Geography.

\section{Introduction.}

Today, many universities, following an Australian lead, publish graduate attribute statements that declare the individual qualities that graduates will display as a collect. The main driver has been graduate employability, a marketing device, couched in arguments about individual performative skills and the development of professional human capital for the new global 'knowledge' economy (Bridgstock, 2009). A second theme concerns citizenship, social inclusion and sustainability, which some express in global terms (Bosanquet, et al., 2012; Clifford and Haigh, 2012). A third addresses individual development, the building of 'good character', socio-cultural values and personal literacies - such as ethical awareness and critical thinking (Boyd et al., 2008; Haigh and Clifford, 2011). AQAL Integral mapping of an array of Graduate Attribute statements shows that the most neglected are these key, individual interior, spiritual rather than performative, attributes of the self, which many might regard as key qualities in an educated person (Haigh and Clifford, 2011). Critical thinking, combined with compassion, is the third eye of an educated citizen; something that allows 


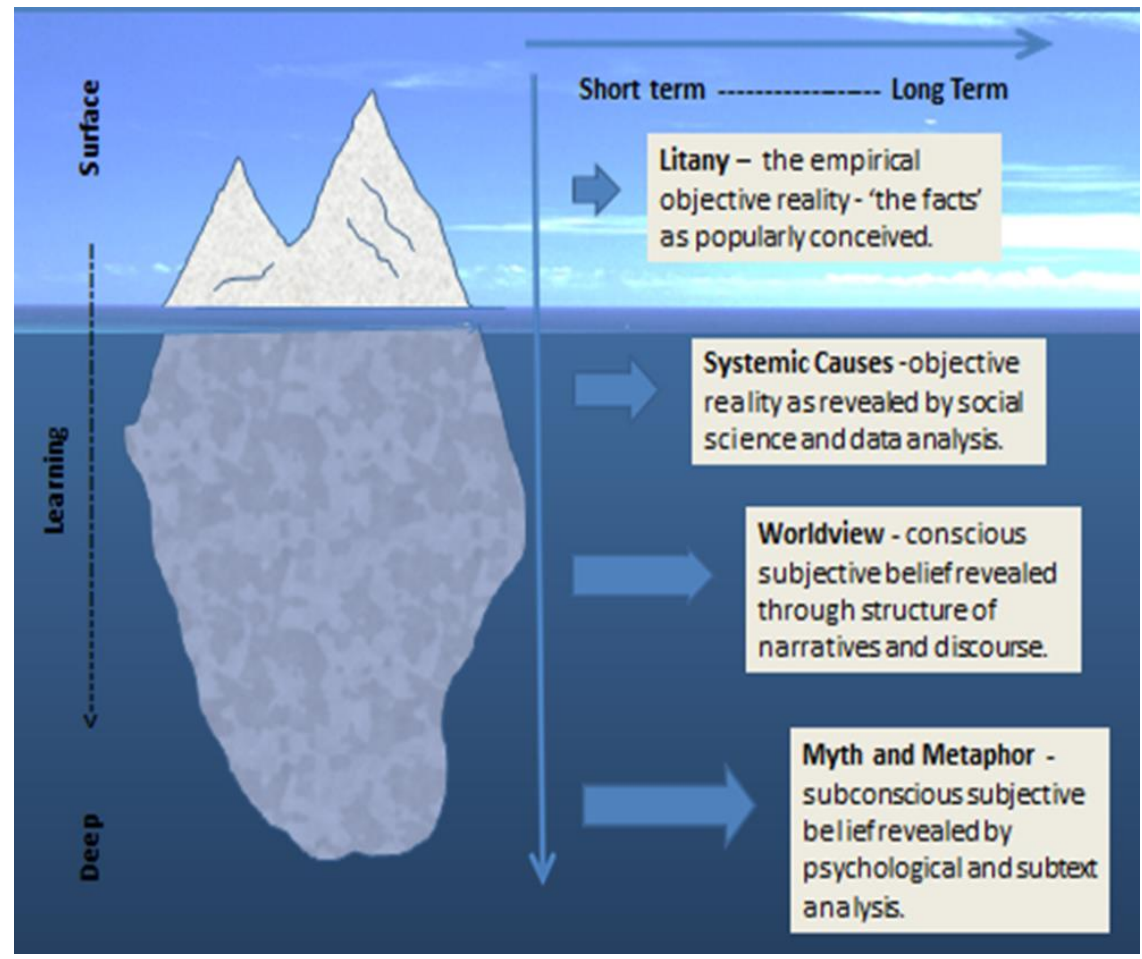

Figure 1. Four Levels of Causal Layered Analysis

them to understand more than they are told and to know when they are being misled by appearances (Rege, 2009).

Encouraging learners to explore beneath the surface of the problems that they investigate is an eternal challenge of undergraduate education. Applying critical thinking, achieving critical depth, are mantras of Higher Education but, other than promoting mimicry, little attention is paid to how to help learners search for deeper understanding. The aim here is to describe and demonstrate a simple yet potent methodology to help undergraduate learners delve beneath surface appearances. Sometimes, critical thinking is linked to the Western culture (HEA, 2013) but, in fact, the arts of seeking the reality that lies beneath surface appearances are much more highly developed within the Dharmic traditions and the method discussed here has deep roots within Dharmic thought and the ontological primacy it awards to consciousness (Inayatullah, 2002).

Dharmic thought differs from Western in its refusal to reify material well-being, competitive performance or deference to elites defined by economic rather than spiritual or ethical power. The Dharma paradigm in education is founded in a worldview that accepts diversity and pluralism, that includes the laws of karma as well as rebirth and liberation, and that displays a value-set that includes non-harming (ahimsa), truthfulness, restraint and dutiful service detached from any wish for personal gain (Haigh, 2010). The Dharmic traditions also share an awareness of the spiritual, unity of all life that manifests in deep concern for environment and sustainability (Long, 2013). For such reasons, Milojevic (2005) includesthese ideas within her larger set of "Spiritual Alternative Visions of Education".

Sarkar (1969, p. 18) writes:

Though the human society is one and indivisible, still there are certain differences in the attitudes to life and the world between the East and the West.... The East, throughout its 
development, has maintained a subjective approach, whereas western countries put great stress on objective development. ... We can build up an ideal society only on the basis of a happy adjustment between the subjective and the objective approaches.

Secular Western thought conceives itself within a historically mitigated but essentially material reality, while Dharmic thinking views the material world as a mirage created by deeper levels of the consciousness. Most modern Dharmic pedagogies are self-conscious hybrids that, like Sarkar, attempt to combine the best of both East and West (Haigh, 2010; Sharma, 2002).

Causal Layered Analysis (CLA), a 'Post-structuralist, 'Neohumanist' approach developed within Futures Studies, provides a simple structure for learners that enables them to unlock layers of deeper meaning within any situation or discourse (Inayatullah, 1998). CLA is founded in the argument that "the most positively useful critique operates self-consciously out of the deepest layers" (Slaughter, 2004, p92). The approach grants exceptional power to metaphor, language, and root cultural myths and contains the idea that both the future and the past are created by the root narratives of the present (Milojevic, 2006, p.221).

In this study, CLA method is deployed in classroom settings, to help final year undergraduate learners to develop a deeper than usual critique of the substance of Geographical discourse through applying CLA to a recent event (the Olympic Games), to their learning, to themselves and to a conventional Geography term-paper. The aim is to build the habit of deeper critical inquiry and a set of personal and research literacies that many regard as key attributes for any graduate.

\section{Western Definitions of Critical Inquiry.}

According to Sumner (1906 p. 633), "Education in the critical faculty is the only education of which it can be truly said that it makes good citizens". Critical thinking has been called "a defining concept of a Western University" (Barnett, 1997, p2). The concept underpins much of the modern pedagogy of Higher Education and Professional Development (Moon, 2008). Critical Thinking pedagogy aims to develop "cognitive skills and affective dispositions" that lie at the core of what it means to be an educated person (Facione, 1990, p2). It is a contested topic, especially by those who dislike the negative associations of the word 'critical', but its real meaning here is questioning of the evidence that supports of any particular form of belief or knowledge claim (Glaser, 1941). As such, it is associated with the development of deep approaches to learning. Glaser (1941) adds that it also includes a willingness to undertake such questioning and knowledge of the methods that permit this kind of inquiry and, as such, links to the pedagogies that promote deep rather than surface learning. Critical thinking combines the disposition to ask probing questions with substantial knowledge of both relevant subject matter and methods of inquiry (Mason, 2007). It is an informed, sceptical, reasoned and reflective approach to information and to the observed world and, as such, links to the pedagogies thatpromote deep rather than surface learning.

\section{Causal Layered Analysis}

Causal layered Analysis (CLA) is a technique from Futures studies that aims to create the 'narrative foresight' needed to create a preferred future from an array of possible futures (Inayatullah, 2013, 2008). It is one among several layered methodologies, which include the AQAL Integral macrostructure (Wilber, 2000, 2003; Beck and Cowan, 1996; Haigh, 2013), 
Generalised Layer Methodology of Voros (Voros, 2005), and the depth layers of Slaughter (Slaughter, 1999). Any of these might be useful for geographical learning because they all require learners to construct insights into the nature of the narrative structures that underpin social processes, albeit in different ways.

Currently, CLA is employed as one part of a 'six pillars' approach to foresight where it is used to deepen understanding by the explore root metaphors than underpin stakeholder viewpoints (Inayatullah, 2008). These six are 1 futures mapping; 2 emerging issues analysis; 3 timing the future using 'macrohistory' (e.g. Sarkar, 1967; Graves, 1974); 4 Causal Layered Analysis; 5 exploring alternative scenarios and 6 . transforming the future through 'envisioning and back-casting'. A case study of BRAC University, Bangladesh, illustrates how the approach can help participants go beyond present understandings and explore the interactions between emerging issues and deeply embedded social narratives (Inayatullah et al. 2013).

CLA explores a sequence of four layers, which represent the multiple dimensions of social reality and their operation at different epistemological levels (Inayatullah, 2012). The four layers of CLA are 1 the Litany, 2 Systemic Causes, 3 Worldview, and 4 Metaphor and Myth (Figure 1). Typically, CLA is represented graphically as an iceberg where, of course, only a small part is visible at the surface (Figure 1). Analysis proceeds downwards from surface appearances towards causal depths that are ultimately subconscious.

\section{Litany}

The Litany is the upper, most visible, layer of surface appearances and events. The Litany is constructed from the conventional wisdoms and traditions that generate the representations of an issue in the media; it is popular understanding, the 'word on the street', and it interacts with an official, often politically mediated, view of reality. Its timescale is very short term, from the here and now to a few months. In Geographical Education, the Litany is the received wisdom of lectures, textbooks, readings, 'facts', statistics, concepts, theories that fuel the term paper, project, quiz and examination machineries of acceptable Geographical knowledge, thinking, curricula and assessment (cf. Bussey, 2009). Underpinning layers are less visible, which is why, when this structure is portrayed as an 'iceberg', with only the Litany appears above the water (Figure 1).

\section{Systemic (Social) Causes}

The Systemic Causes layer is that of conventional Geographical and Social Scientific analysis. It aims to articulate the social, economic, cultural and environmental drivers of particular situations and their interactions. It is expressed in terms of system interconnection, technical explanation, sociocultural and policy analysis. In search for causal motivations, it may analyse, engage and critique different theories, ideologies and institutions using the language of trends, forces, flows and processes. Its timescale is often expressed in terms of years or a few decades.

In Geographical Education, this layer concerns the social construction of the discipline, the cultural and social thought that creates the design of curricula, subject benchmarks, the recognition of key skills and graduate attributes (Clifford and Haigh, 2011), the politics of policy formulation at disciplinary, institutional and national levels. In sum, these are the social processes and cultural norms that construct the Geographical education. 


\section{Worldview}

In AQAL Integral, worldviews are the majority ${ }^{\vee} M E M E S$ that provide the value-based layers of Spiral Dynamics (Wilber, 2000, 2006; Beck and Cowan, 1996). The Worldview Layer engages discourse analysis; it explores cultural values and aspirations, language with its strata and metafunctions (Martin and Rose, 2003), traditions, religious beliefs, and the kind of broad civilizational consensuses that define culture, class, nationality, and systems of socio-political organisation. In Geography, this includes the Eurocentric and often elitist realms of critical social theory, cultural geography and philosophy. The timescale of the Worldview Layers, for example the Western Enlightenment Worldview or Tantric Worldview (Flood, 2006) is expressed in centuries or many decades.

In most Geographical Education, this Worldview layer manifests as a largely subconscious ground of culturally-mediated presumption and discourse manifested as a: "commitment to enlightenment reason and scientific method and a peculiarly Western aesthetic" Bussey (2009, p.21). More generally, there is the materialist commitment to output, demonstrable skill, and competitive merit; a worldview that aspires to create an individualist, achievement-oriented, meritocracy and that uses objective economic criteria to gauge the success of its products. This so-called 'flatland' worldview, which is concerned only with the objective exterior of its products maps onto the 'Orange' value system of Spiral Dynamics (Wilber, 2000). It is also one of the major obstacles to those who believe that education should be about personal development and transformative growth, which alternative value set is a key to a different worldview that guides much of the discourse within this journal and in Higher Education in general. "Values lie at the heart of systems. They are the glue that holds the world together. Change the values and you change the system" (Bussey, 2010, p. 102).

\section{Myth and Metaphor}

Deepest of all is the fourth layer of myths, meta-narratives and metaphors, with all their unconscious emotive dimensions. This encompasses learning gained, often literally, at Mother's or Grandmother's knee and sometimes from social manipulation by peers, leaders, and the media, not least modern computer games. This is the level of ingrained archetypes, 'gut-feelings', and stereotypes, many drawn from the 'truths' learnt in childhood through fable, school-yard, and cultural or religious teaching. It includes the pre-rational, hence uncontested, narrative of fables, those communal and personal stories that embed ideas of social value, role, origins, right and ethic as well as the roots of social group, national and religious chauvinism.

Most importantly, it conveys a sense of rights as well as rights and wrongs that combine to create the rationalised value systems of the worldview layer. Of course, it is right for the strong, handsome, prince to kill heathen foreigners and wild animals, to carry away his fluttering princess, to dispatch any obstacle king, especially if ugly or old, and so become wealthy and thus admirable! Such childhood myths and their embedded servant metaphors drive social delights that include 'phallocratic sexism' (MacPherson, 2011), racism, nationalism, and the amoral processes that reify celebrity, 'glamour', money and power. It is said that it is easier to slay a dragon that to kill a myth and its associated metaphors, 'for these dark trees have very deep roots in the soil of the subconscious, which often entwine deeply with buried desires' (Gabriel, 1991).

Gregory Bateson suggests that metaphor is "how the whole fabric of mental interconnections holds together"(Bateson and Capra, 1988, pp 76-77). The reason is that metaphors work by association, 
they compare things that share similarities but also dissimilarities and they add value by, often subconscious, transference. Problems arise because, sometimes, the extra baggage that travels with a metaphor sets off a train of associations that railroads the thought processes of the thinker.

"The logic of the emotional mind is associative; it takes elements that symbolize a reality, or trigger a memory of it, to be the same as that reality. [Metaphors] speak directly to the emotional mind ... a single part evokes a whole" (Goleman, 1996, p.294).

Metaphors have foundational status. Stephen Pepper argues that our metaphysical root metaphors or 'World Hypotheses' (Pepper, 1942), which argue that, for example, the world is like a machine or the world is like a living organism, are the core structures upon which all learning and comprehension is constructed. Vedic tradition holds that these deep understandings emerge from communicated testimony mitigated by personal, emotion-inducing, experience and (often intuitive) reasoning (Suhotra, 1996). In sum, myths and metaphors are things of extraordinary power; they shape the way the world is conceived, they subconsciously direct thought, and they shape both attitudes and behaviours. This is why exploring the myth and metaphor that both underpin and provide underlying narrative frameworks is a most important form of deep inquiry.

Of course, much Higher Education, including Geographical, is wedded to its own materialistic Western enlightenment-derived mythology, which claims that the world is wholly knowable through rational observation, analysis and measurement and that our maps, models and theories display Truth. Its Materialist World Hypothesis or root metaphor includes the idea that the sensory and empirical and material world is the only world that exists and so confines discussion to that which is observable, objective and measurable. If this were not so, then Geographers would not grade its students for their written products but for other manifestations of their personal development such as emotional intelligence. Of course, by this process, Geographical Education loses the subjective interior, whereupon "meaning and significance are collapsed into valueless facts and meaningless surfaces" (Wilber, 2000, p.75).

Using Causal Layered Analysis.

Causal Layered Analysis (CLA) helps learners discover and unlock layers of deeper meaning within a situation, text or discourse by drawing attention to layers of causation that underpin and drive its surface descriptions and objective 'facts' (Inayatullah, 1998, 2004; Slaughter, 2004).. It is "a hinge concept that allows for structure to be unpacked via method" (Bussey, 2009, p.19).

However, plumbing depths of embedded meaning is not the end of the process. The purpose of CLA is to move on to determine how these deep layers affect the narrative lines of the present and direct the emergence of different possible futures. Inayatullah taunts: "Have you purchased a used future? Is your image of the future, your desired future, yours or is it unconsciously borrowed from someone else?" (Inayatullah, 2008, p.5). He argues that if the underpinning myths, metaphors and worldviews that underpin the litany and social causes of the present are understood, then it is possible to affect the narrative development of future. In fact, "This is exactly what others are doing now - consciously or subconsciously!" (Inayatullah, 2013). Of course, this possibility is something that every learner should, consider. 


\section{Case Studies: Using CLA in the Classroom}

The following sections describe outcomes from encouraging students to use CLA in the context of a third year, final semester module called 'The Ethical geographer and the Geographical Imagination', at Oxford Brookes University, which enrolled 35 learners during 2013 and 31 during 2014 (Boyd et al., 2008). In 2013, the students were set an array of CLA tasks that included a preliminary in-class exercise and the analysis of a suite of lectures based on Gold and Revill (2004), which encourages students to analyse representations of the environment "conveyed by such media as paintings, photographs, newspaper reports, novels, poetry and buildings" Gold and Revill (2004, p. xvii); in CLA terms, by the Litany. Learners were also encouraged, since this course develops reflection upon personal ethics and critical self-awareness (Boyd et al., 2008), to construct a CLA of their own learning. The in-class preparatory exercise was collected-in as the class register in both 2013 and 2014, although some learners rewrote their analysis for their learning journals. Further reports from 2013 formed the first of five parts in an assessed learning journal submitted towards the end of the module. Unusually, it was a requirement that the learning journals were hand written both in an attempt both to reduce copy-and-paste and, by preventing updating, to allow learners to review their development through the course.

During 2014, the structure was changed and, after the initial in-class exercise, the class was directed to produce a team research presentation on a futures-oriented topic of their own choosing by means of either CLA or the AQAL Integral (Haigh, 2013) methodology. The output from this study was assessed by a team spoken presentation and by a conventional individual type-written report.

In both years, participants were invited to grant written permission for their anonymised work to be used in research. They were also asked to consent that their submitted work might be used in research publications. In both years, several students variously declined to gift this permission, expressed disquiet about this use of their work, did not return their consent forms, or did not participate in the exercises. When all such cases are excluded from the study, the data base reduces to the works of about 55 learners across two years.

Preparatory In-Class Exercise (2013 and 2014)

The challenge for the introductory exercise was to find a topic that had been the subject of massive media attention and punditry and that offered very obvious contradictions between its original founding 'intent' and current media narratives. In 2013 and 2014, the London Olympic Games and subsequent Sochi Winter Olympic Games seemed both to meet these specifications and provide a useful link to the Geographical publications of my co-teacher on this course, John Gold (e.g. Gold and Gold, 2008).

In CLA terms, then, the invitation issued to learners was to parse out the four CLA layers for the Olympic Games (Figure 1). This included: 1, the Olympics Games Litany as represented by media reports; 2 , the systemic causes and drivers causes that affected decisions involving the games, their character, marketing and staging; 3 , the underlying discourses that motivated both the application to host the games and hopes for outcomes as well as the worldview that these demonstrate; and, finally, 4, the underpinning, often competing, myths and metaphors of the nation, culture and original Olympic vision. The exercise allows a lot of scope but it proved challenging to learners who 
were new to CLA and to the concepts contained by its deeper layers. Figure 2 displays and critiques a typical product.

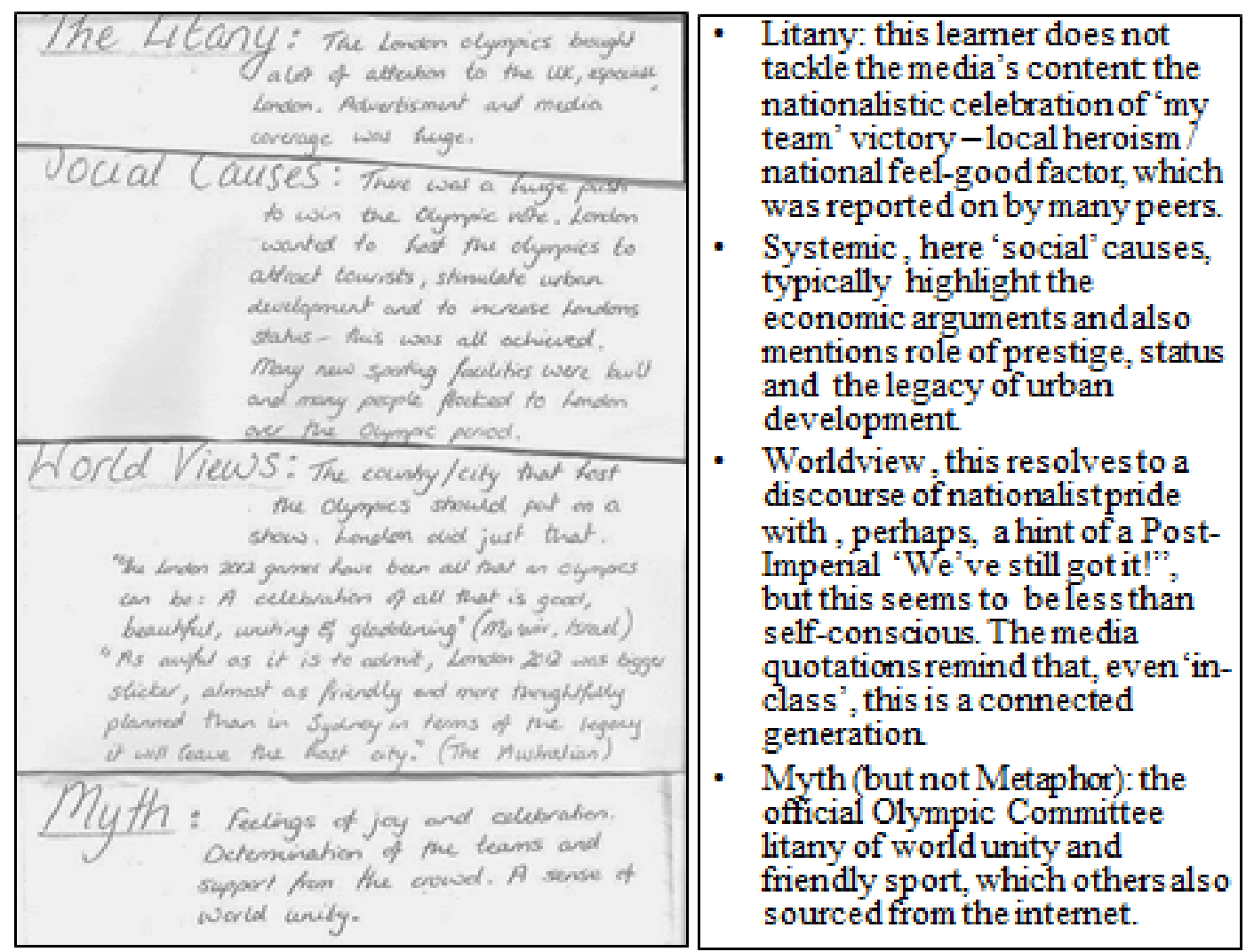

Figure 2. Olympic Games 'in-class' CLA - Coursework Sample and Commentary.

Figure 2's author clearly sees the contradictions between the aspirations of world unity contained by official Olympic mythology and the surface layers of chauvinism. Obviously, this was a first try with a new technique. However, it highlights the benefits of the method through demonstrating the problems that learners recognise when trying to detect those deeper unfamiliar lower layers of Worldview, Myth and Metaphor. The nationalistic and post-Imperial undertones in the surface layers appear but are not explored in the worldview layer. The layer of myth and metaphor offered is, clearly, unrelated to the structures above. The official Olympic discourse of friendly sport and world unity is contradicted by the media emphasis on national medal tables and its undertones of national economic and status gain. Clearly, the discourse is being led by other ideas, which, ideally, could be explored through classroom discussion.

In 2013, the main CLA exercise invited learners to deconstruct their understanding of Geography by reflecting upon the whole of their course of study and particularly the lectures of the following three weeks (Gold and Revill, 2004). In reality, learners focussed on constructing CLAs for the topics of these lectures and recording these in their coursework 'Learning Journal'.

Another sample of coursework, from a 'Learning Journal' discusses Walter Crane's 1886 triumphalist map of the British Empire, which has long been celebrated for demonstrating that cartography is a language of power (Biltcliffe, 2005; Fig. 3). Biltcliffe's deconstruction is not a CLA but it contains the 
depths that a CLA might draw out of learners. The map is framed by personified Britannia symbolising "the all-powerful civilising force of Great Britain" and by "essentialist stereotypes of indigenous peoples that legitimise colonial appropriation" (Biltcliffe, 2005, p.6), not to mention a map projection that exaggerates the size of the British-dominated territories and places Britain at the centre of the world. Within this statement of Imperial power and pride, Biltcliffe (2005) finds a complex interplay between ideas of social reform, the dignity of labour and the Empire as vehicle for the spread of socialistic ideas. More dramatic is the economic message that includes the mapped trade routes, the South African 'cornucopia', the Australian farmer, the laden Indian labourer', Canadian fur trapper, and so on.

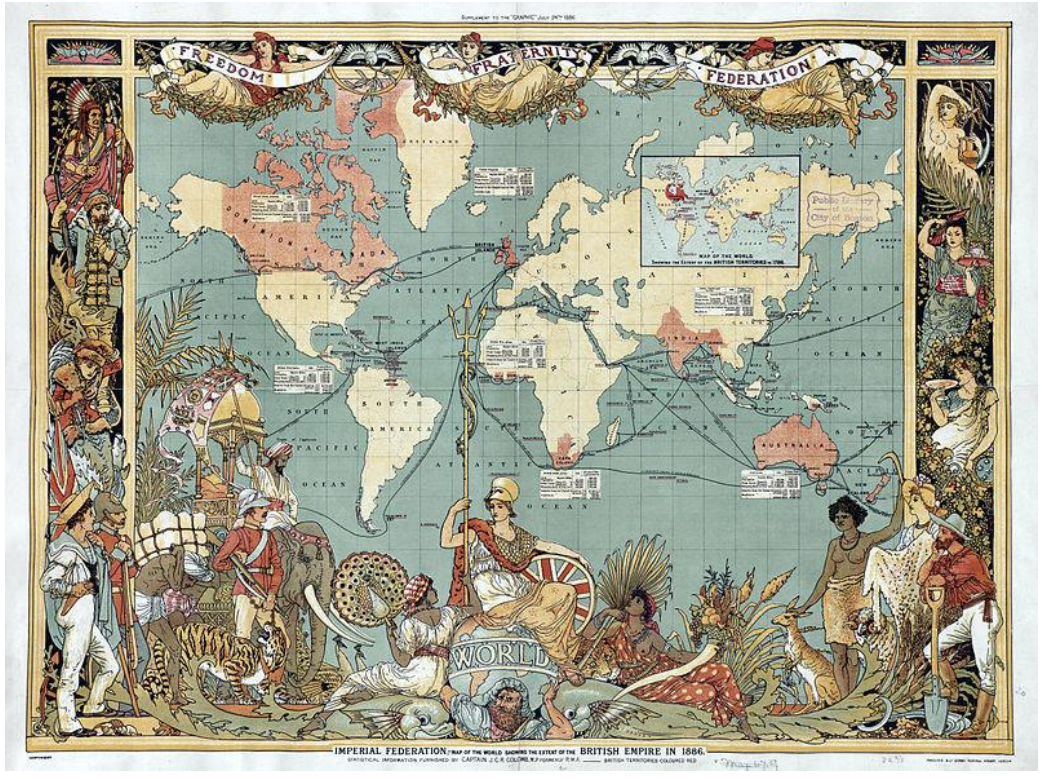

Fig. 3 Walter Crane (1886) Imperial Federation Map Showing the Extent of the British Empire (public domain) (cf. Biltcliffe, 2005).

This map made a great impression on learners and was a popular topic for CLA. Fig 4 is a concise but otherwise fairly typical of the output in the Learning Journals. As in the Olympic Games preparatory exercise, the learner struggles with the lower layers of Worldview, Myth and Metaphor, shies away from the economic and, here with obvious discomfort, from criticism of the British. The text also shows problems in preserving thematic consistency between layers or acknowledging that inconsistencies between layers might have consequence. Most other topics selected for CLA analysis in the learning journals were less incendiary but equally challenging and demonstrated the same abiding problems in learners coming to grips with the deeper layers of analysis and with maintaining the causal consistency between layers that prevents the mixing of narratives.

\section{CLA of Learning}

A metacognitive learner is one who is able to control their own cognitive processes; they know how to know and, hence, self-optimise their own ability to learn. It is a hallmark of a self-directed and self-aware reflective practitioner. Encouraging learners to undertake a CLA of their own learning was an attempt to help them refine a key personal literacy. However, it was also a step too far for many and relatively few attempted the exercise. Figure 5 is the output from one who included this work as part of the conclusion to their learning journal. 


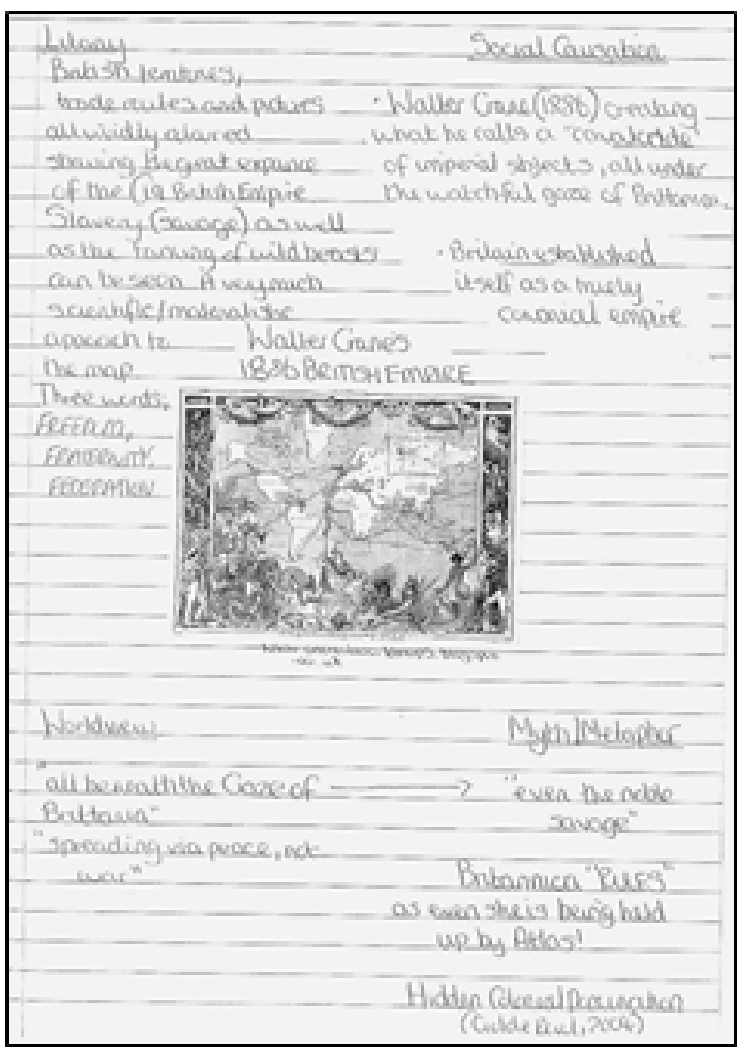

Litany- The maps imagery is expressed in terms of trade routes, slavery is mentioned as also the text: Freedom, Fraternity, Federation. Inappropriately, the statement on a 'scientific/materialist approach, which belongs to the worldview layer, is incorporated.

Systemic (Social) Causation - unpicks the imagery with help from the textbook - the imperial gaze over subject peoples, the colonial but not racial subtexts. Others in the class made more of the economic arguments of the map.

Worldview: The concept of a benevolent civilizational force is mentioned if not extracted but it is implicit.

Myth: The myth of the 'Pax Britannica', of course, aping 'Pax Romana', which is supported by God (Atlas), is obviously in the learner's mind. However, this is not the case for the deeper socio-economic messages, addressed by Biltcliffe (2005), and even the themes of exploitation and control in the textbook chapter where the map appears (Gold and Revill, 2004, p 169 et seq).

Figure 4. CLA from Learning Journal of Crane's Imperial Federation Map (1886) and Commentary.

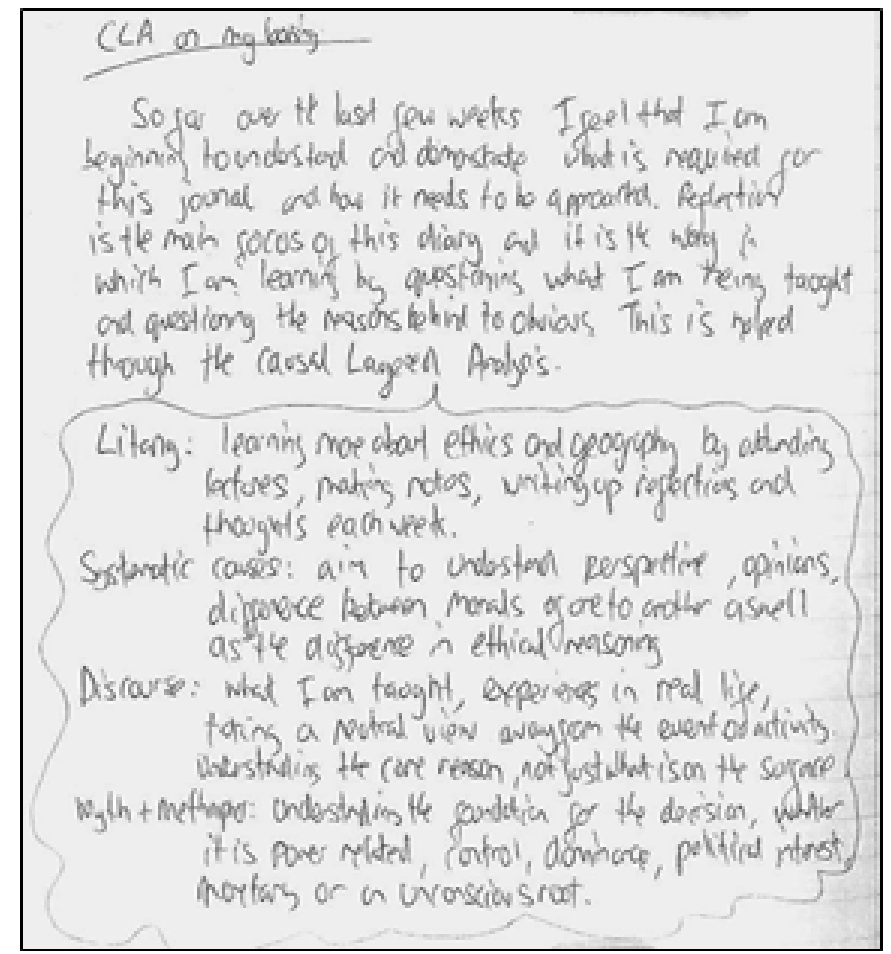

Quote: ${ }^{\prime \prime}$ Reflection is the main focus... and it is the way in which I am learning by questioning what Iam being taught and questioning the reasons behind the obvious"

Litany: ethics and geography

Systemic Causes: difference between morals, and ethical reasoning. Discourse: real life/ neutral view/understanding core reasons/ not just the surface.

Myth: to understand the decisionyou must understand its motivation - whether conscious or unconscious.

Figure 5. CLA from Learning Journal of 'How I Learn'. 


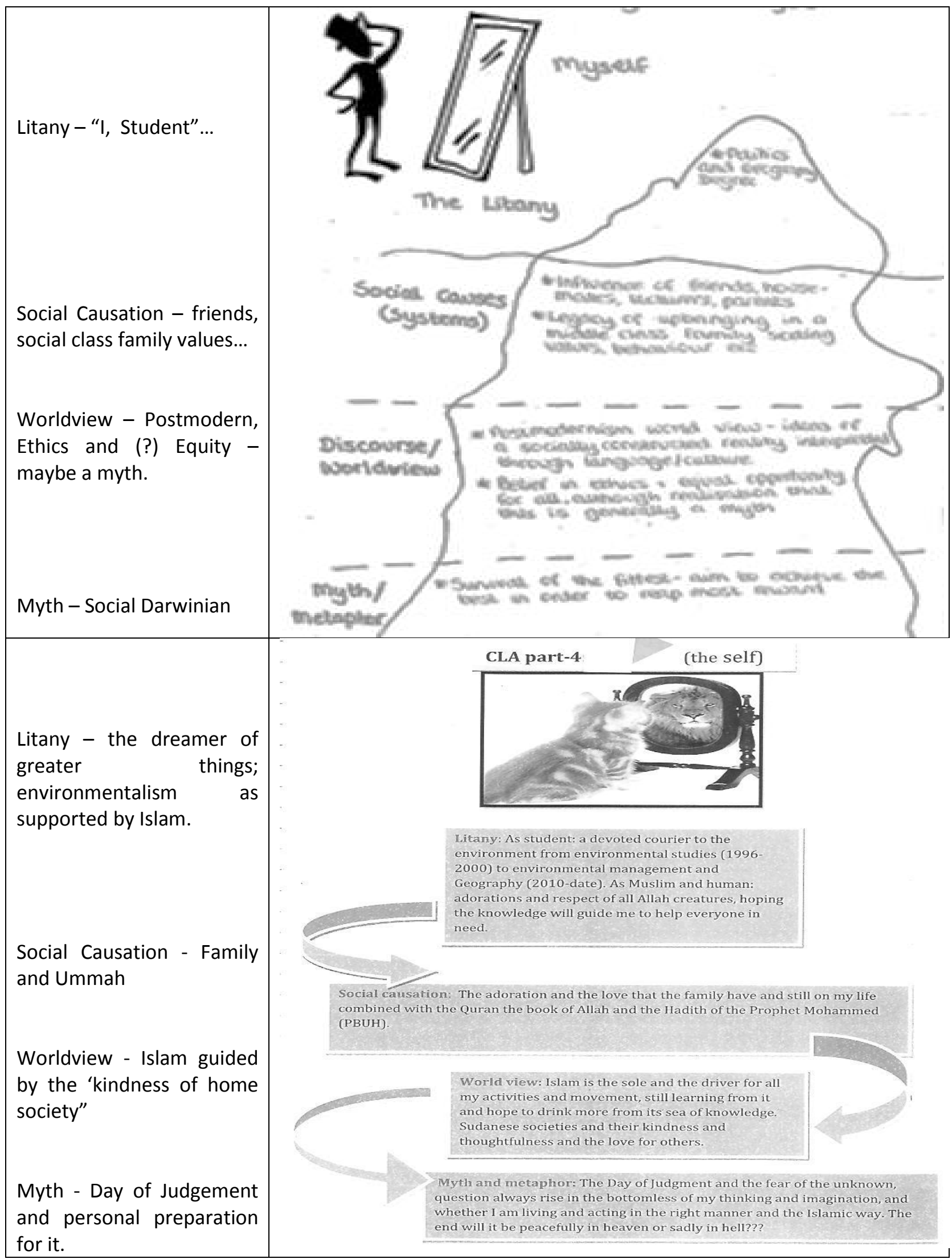

Figure 6. Two contrasting student self-assessments using CLA.(previous page) 
Figure 5 follows several CLA efforts by this learner, who had begun to use this kind of CLA four layer sketch as a launch pad for further discussion of each topic. The example displays an aspiration to probe beneath the surface and to move beyond a single depth layer of questioning. Once again, despite subsequent classes and coursework on Worldview, Myth and Metaphor, the attempt to delve beneath the level of Systemic and Social causes, the usual level of Geographical explanation, is held back by an unwillingness, or perhaps inability, to connect ideas with any general category of worldview or with underpinning layer of myth and metaphor, although the notes clearly signal an recognition of this need.

\section{CLA of Self}

Nouvelle Vague Director, Claude Chabrol remarks that he likes mirrors "because they let one pass through the surface of things" (Berthomieu et al, 1995, p2). Mahatma Gandhi says that liking what you see in the mirror begins when what you think, what you say, and what you do are in harmony. One of the more popular coursework invitations for the learning journal exercise, in a course that stressed personal ethics and responsibility, was to CLA 'yourself', which many explored in wider terms than simply exploring how best they learn. Figure 6 displays two CLA sketches of the outcome of this exercise.

\section{CLA of the Future [Page 175 starts here:]}

The 2013 results revealed a major weakness. While many learners proved capable of breaking their topic down into the different layers, few demonstrated an ability to build their predictions for the Future upwards from the base so created. In 2014, the course was reshaped with methodologies taught at the start, Geographical content following later, and the main coursework exercise required learner teams to use one of the methodologies on offer to assess the future of a geographical topic.

Among the most interesting, learner-selected, CLA topic addressed was the future of 'Freetown Christiania', a former squatter settlement in Copenhagen, which since 1973 has been granted official status as a social experiment (Thörn et al, 2011). Learners address its litany of being a self-sustaining micro-society, tourist attraction and people's movement that is nevertheless beset by heavy association with crime and economic dependence on the drugs trade. Social causes include the counter-cultural revolution of the 1960s as well as socio-economic dissatisfaction and the search for an alternative society. Worldviews include the disparate but contrarian attitudes of diverse stakeholders, an anti-capitalist, anarchic, ideology and a set of Utopian, Ecotopian myths and metaphors that it shares with wider Danish society concerning freedom, community and local democracy, which have so far helped the settlement to survive legal challenges from the State. Problems begin when the learners try to carry these ideas forward although several note that such developments are at odds with the rival mainstream utopian ideals of Neolibralism, which reifies private property and economic growth. Most predict that the settlement will survive as a kind of hippy-'Disneyland', a fantasy utopia, an exhibition where past revolutionary dreams are commodified through T-shirts and tourism and, as such, which may persist even if and when its drugs-trade is 'cleaned-up'.

Another team tackled water management in the Colorado River Basin, especially 'Minute 319" and the hope to revive the Colorado delta in Mexico by the release of waters to mimic spring floods (Sanchez and Coretz-Lara, 2014). The Litany is explored through sources such as National 
Geographic and focus on international cooperation and that the programme will bring the lower Colorado 'back to life'. Systemic Causes explored include American chauvinism, the Hoover Dam, and the water resources needs of the agricultural lands along the Colorado together with interstate water negotiations, which are offset against Mexican perceptions of inequity. The Worldview layer explores the American Neoliberal self-perception as a global economic super-power, a force for civilization and development, a view not much shared south of the border, where ideas such as power-dominance and exploitation hold sway. Finally, taking a lead from the course textbook, the mythology and metaphoric language of 'the taming of the boundless American West' and its development by 'tough, self-reliant, pioneer individuals' is explored. The authors recognise that both the worldviews and core myths of the key stakeholders differ greatly. They argue that both sides will need to reorient their myths and metaphors around the notions of sustainable development if the goal of effective water management is to be achieved.

Unfortunately, while the 2014 experiment showed that learners were capable of building critical visions of future needs that were informed by CLA, few thought to reconstruct the litany, layer-bylayer from the base. This meant that conclusions were based on generalizations drawn from the lower layers but the full implications of these conclusions were not evaluated critically. This pitfall might be avoided by specifying the requirement in the exercise's rubric and providing an illustration (e.g. Pryor, 2014)..

\section{Discussion.}

Causal Layered Analysis (CLA) offers a simple means by which learners can be encouraged to seek beneath the surface appearances of Geographical processes and achieve greater critical depth in their analysis. The strength of CLA is that it encourages learners to look deeper than conventional geographical analysis, which tends to focus on the second layer of systemic causes and much more rarely the stakeholder worldviews that drive them (Inayatullah, 1998). Developing a different layered model, Walkington and Wilkins (2000) show how worldview may influence the practice of Geography teachers and the sophistication of their approach to citizenship education. However, in this study, even in 2014, where the exercise was an end-of-semester and end-of-degree task that followed overtly preparatory sessions devoted to both worldviews and the power of metaphor, as many as a third struggled to identify these foundational layers. Clearly, this highlights the tendency for much Geography to concentrate on the layer of systemic causes without considering the philosophies and culturally-mediated traditions that drive those causes. Critical evaluation of geography's mainstream worldviews may be provided by feminist writers, by the Socialist, 'Marxist', perspectives of the past, and by a rising crescendo of non-Western voices but these remain at the margin.

Exploring alternatives to "the western civilizational and patriarchal framework", Milojevic (2005, p. 250) notes "there are certain myths and metaphors that make the story function as true". The role of myth is often explored in the context of cultural geographies, albeit from a mainly Eurocentric perspective, and this was the case in this course (Gold \& Revill, 2004). Here, most learners were happy working with myths like that of the "American West" or utopia and considering how these would translate into future-making through action or policy. However, they were purblind, initially, to the broader mythology and metaphors of Western society. Of course, studying the "other" commonly provides the mirror by which 
the self is understood. Exploring the "other" can help initiate questioning about all those deep rooted myths that constrain the way that one's own reality is imagined and futures created. One important benefit of applying CLA is that it helps expose key personal ideas, narrative subtexts and cultural beliefs that might otherwise go unquestioned. Critics argue that CLA, in keeping with its post-structuralist/future studies roots, like much geography, emphasizes the socioculturally constructed collective over the individual subjective [Page 177 starts here] interior (Riedy, 2008). However, learners see themselves as individuals and so CLA is easily applied to introspection. Indeed, this application lies closest to the layered methodologies of its Dharmic roots (Avadhutika Anandamitra, 1999). Here, CLA is used to help learners explore their personal (meta-cognitive) awareness of their own learning and to help them understand their self and its motivations. Of course, self-awareness or personal literacy is a key graduate attribute and an important component of emotional intelligence, a key component of work place excellence (Goleman, 1996).

CLA exposes the roots from which the future may grow (Inayatullah, 1998). Each progressively deeper level "reveals a deeper cause" (Inayatullah, 2014, p. 1). Each layer shows how the deep myths and metaphors of different stakeholders construct both problems and their solutions and so provide a guide for strategic planning towards "an alternative future that is robust in its implementation" (Inayatullah, 2014, p. 1). The task of the analyst resolves to extrapolation of the future(s) that grow(s) from these roots. However, in class, learners find it easier to use CLA for analysis than scenario formulation. The tendency is to treat each layer as a separate entity rather than a layer of causation. Most students are comfortable with the idea that CLA is a way of deconstructing the present to discover its causal processes. Most also accept, at an intellectual level, that our "myths create us" and hence that the lowest causal layers help create the future. However, it is harder to communicate the real power of myth and metaphor. Few learners took the time to analyse the metaphors contained by their core texts. This was despite extended class discussion of the media debate surrounding the shooting of Representative Gabrielle Giffords, whose seat lay in the cross-hairs of a Republican website's gun-sights. This discussion focussed on the violence of the metaphors used in American political discourse, which, very briefly, set the US media on course towards a "metaphor alert" against the use of "military language" (Timpane \& Derakhshani, 2011).

Despite this, there is much in the student journals to suggest that the process of considering the nature and character of CLA's causal layers encouraged learners to think more deeply and more critically about both media portrayals of events and the discourse of social science commentators in the academic literature. There was much greater awareness that there were deeper, mainly subconscious, layers of worldview, philosophy and cultural myth affecting and, possibly controlling, the development of surface events.

This is important because, as Mahatma Jyotibao Phule has shown, education can act as a third eye that opens up new ways of understanding the world and exposes the deeper subtexts that often underpin oppression and so begin to change the world (Chakravarti, 2012). Mahatma and Savitribai Phule, who pioneered women's education and campaigned against class and caste oppression in India (Jha, 2011; Sirswal, 2013), conceived "teachers and students as modern truth-seekers and agents of social transformation" (Rege, 2009, p. 17). Techniques like CLA can help open this "third eye" for learners and make them more aware of the role of cultural myth, metaphor, worldview and tradition on the development of the future and its geographies. 


\section{Conclusion}

Fostering critical analytical depth in learners is a goal of Higher Education. CLA, a technique from Futures Studies, helps analysts discover the drivers that will shape the future (Inayatullah, 2013, 2008). CLA explores these drivers in four causal layers. These begin (Page 178 starts here] with the surface litany of popular and media discourse, below which is the layer of social and systemic causes that provide much of the subject of geography research. CLA continues to explore the deeper layers of worldview, ideology and philosophy that underpin the construction of social causes and, below this, to examine the largely subconscious layers of cultural myth, language and metaphor that control and condition worldviews and philosophy. The approach is simple in concept but its lower layers are unfamiliar to many learners, who may need focussed instruction to gain practical comprehension. However, the results are promising and especially beneficial to middle ability learners who find this structured approach to critical comprehension helpful.

CLA encourages learners to try and see what lies beneath the surface of the things they are taught and things that they read. Its typical applications have been in the post-structural analysis of socioculturally-constructed processes. Of course, in classroom practice, the approach is vulnerable to formulaic "box-filling" by weaker or less engaged learners. The challenge is to convey that the four layers represent deeper layers of causation, that these differ between different stakeholders, and the ultimate challenge is to have learners rebuild the layers from the base up to define possible futures. However, when combined with a multiple stakeholder approach, CLA may help embed lessons of pluralism and enable learners to see the world as others see it, so providing support for the development of critical citizenship (Haigh, Revill, \& Gold, 1995; Walkington \& Wilkins, 2000). CLA encourages learners to reflect upon their personal culture and beliefs and so move towards a postconventional global citizenship (Wilber, 2000). In fact, CLA is especially beneficial when used by learners to examine their own learning, personal motivations and mythologies. Used in this way, it can help enhance the learner's critical self-awareness and emotional intelligence (Goleman, 1996).

CLA is a valuable tool for enabling learners to explore deeper layers of causation and attain critical depth. Its four-layer structure provides a useful framework for inquiry-based learning that is applicable to both geographical research, especially the understanding of contestation between multiple stakeholders, and as a vehicle for self-exploration by individual learners. Used in such ways, the technique promotes the development of core graduate attributes including personal literacy (self-awareness), research training and deeper critical thinking.

\section{References}

Avadhutika Anandamitra, Ac. (1999). Beyond the Superconscious Mind. Kolkata: Ananda Marga Publications.

Barnett, R. (1997). Higher education: A critical business. Buckingham, UK: SRHE and Open University, Press.

Barnett, R., \& Hallam, S. (1999). Teaching for supercomplexity: A pedagogy for higher education.In P. Mortimore (Ed.) Understanding pedagogy and its impact on learning, (pp 137-154). London: Paul Chapman (SAGE). 
Barrie, S. C. (2005, February 11). Graduates for a changing world, Canberra, University ofCanberraTeaching for Learning Showcase. Retrieved December 8, 2014, from http://www.canberra.edu.au/ data/assets/pdf file/0018/8091/UCPresentation SimonB.pdf

Bateson, G. \& Capra, F. (1988). Uncommon Wisdom: conversations with remarkable people (pp 7677). New York: Simon and Schuster (Bantam).

Beck, D.E., \& Cowan, C.C. (1996) Spiral Dynamics: mastering values, leadership, and change, Malden, MA: Blackwell.

Berthomieu, P., Jeancolas, J-P, Vassé, C ., and Positif (1995) An Interview with Claude Chabrol on La Cérémonie. Retrieved from: http://zakka.dk/euroscreenwriters/interviews/claude chabrol 02.htm (27 May 2014)

Biltcliffe, P. (2005). Walter Crane and the Imperial Federation Map Showing the Extent of the British Empire (1886). Imago Mundi 57,1, 63-69. [doi:10.1080/0308569042000289851].

Bosanquet, A., Winchester-Seeto, T., \& Rowe, A. (2012). Social inclusion, graduate attributes and higher education curriculum. Journal of Academic Language and Learning, 6(2), A73-A87.

Boyd, W. B. E., Healey, R. L., Hardwick, S. W., Haigh, M., Klein, P., Doran, B., Trafford, J. \& Bradbeer, J. (2008). 'None of Us Sets Out To Hurt People': The Ethical Geographer and Geography Curricula in Higher Education. Journal of Geography in Higher Education 32,1, 37-50.

Bridgstock, R. (2009). The graduate attributes we've overlooked: Enhancing graduate employability through career management skills. Higher Education Research \& Development, 28(1), 31-44.

Bussey, M. (2010). Fostering new values and stories in Higher Education: what climate change brings to the educational table. Journal of Futures Studies 15,1, 101-108.

Bussey, M. (2009). Causal layered pedagogy: rethinking curricular practice. Journal of Futures Studies 13,3, pp 19-32.

Chakravarti, U. (2012). Re-thinking the Goals of Education: Some Thoughts on Women's Education and Women's Development. Contemporary Education Dialogue, 9,2, 223-243.

Clifford, V. \& Haigh, M. (2011). Graduate Attributes and Education for Responsible Global Citizenship. In: Clifford, V. \& Montgomery, C. (Eds.), Moving towards Internationalisation of the Curriculum for Global Citizenship in Higher Education (pp 93-118). Oxford: Oxford Brookes University, (OCSLD).

Facione, P. A. (1990). Critical Thinking: A Statement of Expert Consensus for Purposes of Educational Assessment and Instruction: research findings and recommendations. Fullerton, CA: American Philosophical Association Committee on Pre-College Philosophy. Retrieved from http://files.eric.ed.gov/fulltext/ED315423.pdf (21, May, 2014).

Flood, G. (2006). The Tantric Body: The Secret Tradition of Hindu Religion. London: I.B. Taurus.

Gabriel, Y. (1991). On organisational stories and myths: Why it is easier to slay a dragon than to kill a myth. International Sociology 6,4, 427-442.

Glaser, E.M. (1941). An Experiment in the Development of Critical Thinking. New York: Columbia University, Teacher's College. 
Gold, J. R., \& Gold, M. M. (2008). Olympic cities: regeneration, city rebranding and changing urban agendas. Geography Compass, 2,1, 300-318.

Gold, J.R. \& Revill, G. (2004). Representing the Environment. Abingdon: Routledge.

Goleman, D. (1996). Emotional Intelligence. London: Bloomsbury.

Graves, C.W. (1974). Human nature prepares for a momentous leap. The Futurist 8,2, 72-87.

Haigh, M. (2013). AQAL Integral: a holistic framework for pedagogic research. Journal of Geography in Higher Education 37,2, 174-191.

Haigh, M. (2010). Education for a Sustainable Future: Strategies of the New Hindu Religious Movements. Sustainability 2,11, 3500-3519. Retrieved from: http://www.mdpi.com/20711050/2/11/3500/pdf. (21 May, 2014).

Haigh, M. (2006). Deep Ecology education: learning from its Vaisnava Roots. Canadian Journal of Environmental Education 11, 1, 43-57. Retrieved from:

http://cjee.lakeheadu.ca/index.php/cjee/article/viewFile/503/400 (23 May 2014).

Haigh, M., \& Clifford, V. A. (2011). Integral vision: A multi-perspective approach to the recognition of graduate attributes. Higher Education Research \& Development, 30(5), 573-584.

Haigh, M.J., Revill, G. \& Gold, J.R. (1995). The 'Landscape Assay': exploring pluralism in environmental interpretation. Journal of Geography in Higher Education 19,1, 41-55.

HEA (2013). Critical thinking (part of the Teaching International Students project). York: Higher Education Academy. Retrieved from:

(http://www.heacademy.ac.uk/resources/detail/internationalisation/isl critical thinking (20, May, 2014).

Inayatullah, S (2014). Causal Layered Analysis Defined. The Futurist 48, 1, art.2. Retrieved from http://www.wfs.org/futurist/january-february-2014-vol-48-no-1/causal-layered-analysis-defined (14 August, 2014)

Inayatullah, S. (2013). Causal Layered Analysis: Sohail Inayatullah at TEDxNoosa. TEDx Talks Retrieved from: http://www.youtube.com/watch?v=ImWDmFPfifl (20 May, 2014).

Inayatullah, S. (2012). Humanity 3000: a comparative analysis of methodological approaches to forecasting the long-term. Foresight 14,5, $401-417$.

Inayatullah, S. (2008). Six pillars: futures thinking for transforming. Foresight, 10,1, 4-28.

Inayatullah, S. (2006). From Multiculturalism to Neohumanism: pedagogy and politics in changing futures. In: Inayatullah, S., Bussey, M. \& Milojević, I. (Eds.), Neohumanist Educational Futures: liberating the pedagogical intellect (pp. 6-20). Taipei, Taiwan: Tamkang University Press.

Inayatullah, S. (2002). Understanding Sarkar: The Indian Episteme, Macrohistory and Transformative Knowldege. Leiden: Brill, pp 54 et seq.

Inayatullah, S. (1998). Causal layered analysis: poststructuralism as method. Futures 30,8, 815-829.

Inayatullah, S., Ahmed, S., Alam, P., Davis, S., \& Hashemi, S. (2013). Alternative scenarios for BRAC University. On the Horizon 21,4, $275-285$.

Inayatullah, S., Bussey, M. \& Milojević, I. (2006). Introducing Neohumanism, in: Inayatullah, S., Bussey, M. \& Milojević, I. (Eds) Neohumanist Educational Futures: liberating the pedagogical intellect (pp. 3-5). Taipei, Taiwan, Tamkang University Press,.

Jha, N.K (2011). Jotirao Phule: social justice. In: Singh, M.P. \& Roy, I.H. (Eds) Indian Political Thought: Themes and thinkers (pp 70-92). Noida, U.P.: Pearson / Dorling Kindersley (India). 
Long, J.D. (2013). The Dharma Paradigm and ethos some insights from Jainism and Vedānta. International Journal of Dharma Studies 2013, 1,2, 1-10.

Martin, J.R. \& Rose, D. (2003). Working with Discourse. London: Continuum.

Mason, M. (2007). Critical thinking and learning. Educational Philosophy and Theory, 39,4, 339-349.

Milojevic, I. (2005). Educational Futures; Dominant and Contesting Visions. Abingdon: Routledge.

Moon, J. (2008). Critical thinking: An exploration of theory and practice. Abingdon: Routledge.

Pepper, S. C. (1942). World Hypotheses: a study in evidence. Berkeley, CA: University of California Press.

Pryor, W. (2014). From crops to care: The changing nature of health care in rural Australia. Journalof Futures Studies, 18, 119-130.

Rege, S. (2009). Education as Tritya Ratna: towards Phule-Ambedkarite Feminist Pedagogical practice. Journal of Indian Education 35,2, 5-36.

Riedy, C. (2008). An integral extension of causal layered analysis. Futures 40,2, 150-159.

Sanchez, V. \& Cortez-Lara, A. A. (2014). Minute 319 of the International Boundary and Water Commission between the US and Mexico: Colorado River binational water management implications. International Journal of Water Resources Development ahead-of-print (2014): 1-11.

Retrieved from http://www.tandfonline.com/doi/abs/10.1080/07900627.2014.922465\#.UycBmNeLSg (14 August 2014).

Sarkar, P.R. (1967), The Human Society, Vol. 2, Calcutta (Kolkata): Ananda Marga. Also in: The Electronic Edition of the Works of P.R. Sarkar (6e, 2001), Anandanagar, WB: Ananda Marga Publications, cd-rom.

Sarkar, P.R. (1969). The meeting of East and West: Talks on Education, Ranchi, India. 'Prout in a Nutshell Part 18', in: The Electronic Edition of the Works of P.R. Sarkar. Anandanagar, WB: Ananda Marga Publications (2001). Also retrieved from New Renaissance Magazine:

http://www.ru.org/index2.php?option=com content\&do pdf=1\&id=150 (20 May, 2014)

Schultz, W. (2010). Models and methods in motion: declining the dogma dance. Futures 42,2, 174176.

Sharma, R.N. (2002). Neo Vedanta Education. New Delhi, Shubhi.

Sirswal, D.R. (2013). Mahatma Jyotiba Phule: A Modern Indian Philosopher. Darshan: International Refereed Quarterly Research Journal for Philosophy and Yoga 1, 3-4, 28-36. Retrieved from http://philpapers.org/archive/SIRJP.pdf (14 August 2014).

Slaughter, R.A. (2004). Futures Beyond Dystopia: Creating Social Foresight. Abingdon: Routledge. Slaughter, R.A. (1999). A new framework for environmental scanning. Foresight 1,5, 387-97.

Suhotra Swami (1996). Substance and Shadow: the Vedic method of knowledge. Zurich: Govinda Press.

Sumner, W. G. (1907). Folkways: A study of mores, manners, customs and morals. Boston: Ginn.

Thörn, H., Wasshede, C. \& Nilson, T. (eds) (20101) Space for Urban Alternatives? Christiania 19712011. Gothenburg: Gothenburg University and Gidlunds Förlag. Retrieved from https://gupea.ub.gu.se/bitstream/2077/26558/3/gupea 207726558 3.pdf (14 August, 2014).

Timpane, J. \& Derakhshani, T. (2011). How the media can defang poisonous political discourse. Philadelphia Inquirer. Jan 11, 2011. at: http://articles.philly.com/2011-01-

11/news/27021867 1 discourse-violence-media-fight (16 August, 2014). 
Vanita, R, (2003). The Self Is not gendered: Sulabha's debate with King Janaka. NWSA Journal 15, 2, 76-93.

Voros, J. (2005). A generalised "layered methodology" framework. Foresight 7, 2, $28-40$.

Walkington, H. \& Wilkins, C. (2000). Education for critical citizenship: the impact of teachers' worldview on classroom practice in the teaching of values. The School Field 11, pp 59-78.

Wilber, K. (2000). Integral Psychology: Consciousness, Spirit, Psychology, Therapy. Boston, MA: Shambhala. 